\title{
Penyusunan Perencanaan Keberlangsungan Bisnis PT PLN (Persero) APD Jateng dan DIY dengan ISO 22301 dan Metode OCTAVE
}

\author{
Azmi Afifah Zahra, Apol Pribadi, dan Eko Wahyu Tyas D \\ Jurusan Sistem Informasi, Fakultas Teknologi Informasi, Institut Teknologi Sepuluh Nopember (ITS) \\ Jl. Arief Rahman Hakim, Surabaya 60111 Indonesia \\ e-mail: apol.pribadi@gmail.com, tyas.darmaningrat@gmail.com, azmi12@mhs.is.its.ac.id
}

\begin{abstract}
Abstrak-Penelitian dalam tugas akhir ini adalah melakukan penyusunan perencanaan keberlangsungan bisnis teknologi informasi pada PT PLN (Persero) APD Jateng dan DIY dengan berbasis risiko sebagai bentuk kesiapan perusahaan dalam menangani risiko dan dampak bisnis yang mengancam perusahaan. PT PLN (Persero) APD Jateng dan DIY menggunakan sistem dan layanan TI sebagai daya dukung perusahaan dalam mencapai tujuannya. Penggunaan sistem dan layanan TI tersebut tidak terlepas dari adanya ancaman pada risiko sistem dan layanan TI serta dampak dari proses bisnis yang dijalankan oleh tiap fungsi bisnis perusahaan. Dalam proses penyusunan untuk perencanaan keberlangsungan bisnis akan dibuat terlebih dahulu alur kerja untuk kegiatan pengelolaan keberlangsungan bisnis (Business Continuity Management) untuk PT PLN (Persero) APD Jateng dan DIY dengan menggunakan acuan ISO 22301: 2012 dan alur kerja yang telah diterapkan oleh perusahaan lain yaitu dari Perusahaan Chubu Electric Power Company Group dan DHS Electricity dengan tetap memberikan prosedur praktis yang dapat disesuaikan oleh PT PLN (Persero) APD Jateng dan DIY. Hasil akhir dari penelitian ini adalah berupa rekomendasi penerapan alur kerja dan strategi keberlangsungan bisnis untuk PT PLN (Persero) berdasarkan pada risiko aset TI yang menjadi tanggung jawab tim SCADA dan Telekomunikasi.
\end{abstract}

Kata Kunci- Chubu Electric Power Company Group, DHS Electricity, ISO 22301:2012, Pengelolaan Keberlangsungan Bisnis (BCM), Perencanaan keberlangsungan bisnis (BCP) berbasis risiko, PT PLN (Persero)

\section{PENDAHULUAN}

$\mathrm{D}$ ALAM rangka mencapai visi dan misi, perusahaan dan organisasi membutuhkan dukungan sistem dan layanan TI untuk menjalankan proses bisnisnya. Namun dalam penggunaan sistem dan layanan TI tersebut tidak terlepas dari risiko TI yang berdampak pada keberlangsungan bisnis. Oleh karena itu perlunya perusahaan dalam merencakanan kebutuhan untuk keberlangsungan bisnis perusahaan untuk menanggapi, memulihkan, melanjutkan proses bisnis setelah adanya gangguan sehingga organisasi/ perusahaan. Perencanaan keberlangsungan bisnis perusahaan dapat didokumentasikan dalam dokumen BCP (Business Continuity Plan) dimulai dengan mengetahui terlebih dahulu dampak bisnis perusahaan dalam aspek finansial maupun operasional apabila proses bisnis perusahaan terhenti atau terhambat, serta penggunaan layanan
TI serta risiko dalam sistem dan layanan TI tersebut. Lalu penyusunan dokumen $\mathrm{BCP}$ dapat disusun dengan menetapkan kebijakan dan prosedur aksi manajemen untuk kejadian bencana.

Pada saat ini, PT PLN (Persero) APD Jateng dan DIY masih belum memiliki perencanaan strategi dan pengelolaan untuk keberlangsungan bisnis berbasis risiko yang terdokumentasi dan tersusun sesuai dengan standar praktis berdasarkan ISO maupun standar praktis dari perusahaan yang telah menerapkan pengelolaan keberlangsungan bisnis untuk perusahaan. Selain itu, dalam rangka menjaga data serta sistem dan layanan TI perusahaan dari keadaan pra dan pasca bencana, saat ini masih belum terdapat alur untuk penanganan backup dan recovery data PT PLN (Persero) APD Jateng dan DIY. Namun saat ini untuk menanggulangi adanya risiko dan dampak bisnis yang mengancam proses bisnis perusahaan, PT PLN (Persero) telah memiliki prosedur praktis yang tertuang dalam dokumen rencana jangka panjang untuk penilaian risiko dan dampak bisnis perusahaan. Sehingga dalam tugas akhir ini, penulis bermaksud untuk menyusun bentuk dari perencanaan keberlangsungan bisnis perusahaan (Business Continuity Planning) PT PLN (Persero) APD Jateng dan DIY dengan berangkat dari penyusunan alur kerja dari pengelolaan keberlangsungan bisnis perusahaan (Business Continuity Management) yang disusun dari formulasi antara ISO 22301: 2012 dan bentuk yang alur kerjan BCM yang telah diterapkan perusahaan lain yaitu Chubu Electric Power Company Group dan DHS Energy. Permasalahan yang akan dijawab dalam penelitian ini adalah mengenai hasil analisis kritikalitas risiko dari sistem dan layanan TI yang digunakan oleh PT PLN (Persero) APD Jateng dan DIY, analisis kritikalitas dampak bisnis pada PT PLN (Persero), bentuk alur kerja BCP yang seusai dengan kebutuhan dan keinginan PT PLN (Persero) APD Jateng dan DIY, serta bentuk rekomendai strategi untuk perencanaan keberlangsungan bisnis PT PLN (Persero) APD Jateng dan DIY.

\section{TEORI PENUNJANG}

\section{A. Manajemen Risiko}

Menurut ISO 31000, manajemen risiko merupakan sekumpulan aktivitas dan metode yang terkoordinasi untuk mengarahkan dalam mengkontrol risiko yang bisa 
mempengaruhi pencapaian tujuan perusahaan [1]. Menurut Blokdijk [2], tugas manajemen risiko adalah mengelola risiko suatu proyek untuk risiko. Tujuan dan manfaat yang dari pelaksanaan manajemen risiko oleh perusahaan adalah untuk mencegah perusahaan dari kegagalan, mengurangi pengeluaran yang berlebihan dari hasil dampak atau risiko yang terjadi.

\section{B. Metode OCTAVE}

Kerangka kerja OCTAVE (Operationally Critical Threat, Assets and Vulnerability Evaluation) adalah merupakan pendekatan yang digunakan untuk menilai kebutuhan kemanan informasi organisasi. Kerangka kerja ini memanfaatkan pengetahuan masyarakat yang berhubungan dengan praktek kemanan dan proses organisasi untuk mengetahui keamanan dalam organisasi [3].

\section{Penilaian Risiko dengan FMEA}

Dalam mengidentifikasi risiko, OCTAVE memiliki kekurangan pada penilaiannya. Dengan demikian, ditambahakan metode FMEA agar dapat melengkapi kekurangan tersebut. Failure Modes Effect and Analysis (FMEA) adalah pendekatan langkah demi langkah untuk mengidentifikasi semua kegagalan yang mungkin terjadi dalam proses manufaktur atau perakitan, atau produk atau layanan [4]. Tujuan dari penilaian FMEA adalah untuk melakukan identifikasi terhadap 3 hal, yaitu penyebab kegagalan, efek yang ditimbukan dari kegagalan, serta mengetahui tingkat kritikalitas efek dari kegagalan tersebut.

\section{Analisa Dampak Bisnis}

Analisa dampak bisnis atau Business Impact Analysis (BIA) merupakan proses yang dilakukan untuk menentukan proses bisnis dan fungsi bisnis yang kritis dari adanya risiko yang menimbulkan dampak yang terjadi pada organisasi/ perusahaan [5]. Dalam tahapan penyusunan BCP, BIA adalah langkah awal untuk mengidentifikasikan aktifitas, penilaian dampak, membuat prioritasi serta mengidentifikasikan adanya ketergantungan antar sumber daya [6].

Dalam proses tugas akhir ini, penilaian dampak bisnis yang akan dilakukan adalah dengan menggunakan metode yang telah diterapkan oleh PT PLN (Persero) berdasarkan pada kebijakan direksi sesuai KEPDIR 537.K.DIR/2010 sebagai fokus implementasi pada risk awareness dalam penguatan kontrol internal [7]. Dalam penilaian dampak bisnis tersebut hanya akan terbatas berdasarkan peninjauan dari aspek operasional bisnis dan aspek produk dan layanan.

Berikut merupakan daftar klasifikasi penilaian dampak bisnis dari aspek produk dan layanan serta aspek proses bisnis internal:

Tabel 1.

Klasifikasi penilaian dampak bisnis pada aspek produk dan layanan

\begin{tabular}{ccc}
\hline $\begin{array}{c}\text { Tingkat } \\
\text { Dampak }\end{array}$ & Keterangan & Nilai \\
\hline $\begin{array}{c}\text { Tidak } \\
\text { Signifikan }\end{array}$ & Mengakibatkan pemadaman sesaat selama <15 menit \\
pada satu waktu & 1 \\
Minor & $\begin{array}{c}\text { Mengakibatkan pemadaman sesaat selama 15 menit }- \\
1 \text { jam pada satu waktu }\end{array}$ & 2 \\
Medium & $\begin{array}{c}\text { Mengakibatkan pemadaman selama 1 - 3 jam pada } \\
\text { satu waktu }\end{array}$ & 3 \\
Signifikan & $\begin{array}{c}\text { Mengakibatkan pemadaman selama 3 jam - 1 hari } \\
\text { pada satu waktu }\end{array}$ & 4 \\
\hline
\end{tabular}

\begin{tabular}{|c|c|c|}
\hline Malapetaka & $\begin{array}{l}\text { Mengakibatkan pemadaman selama lebih dari } 1 \text { hari } \\
\text { dan/atau } \\
\text { Mengakibatkan pemadaman bergilir pada watu waktu } \\
\text { (blackout system) }\end{array}$ & 5 \\
\hline \multicolumn{3}{|c|}{$\begin{array}{c}\text { Tabel } 2 . \\
\text { Klasifikasi penilaian dampak bisnis pada aspek proses bisnis internal } \\
\end{array}$} \\
\hline $\begin{array}{l}\text { Tingkat } \\
\text { Dampak }\end{array}$ & Keterangan & Nilai \\
\hline $\begin{array}{l}\text { Tidak } \\
\text { Signifikan }\end{array}$ & Kegiatan proses bisnis perusahaan tidak terganggu & 1 \\
\hline Minor & $\begin{array}{c}\text { Mengakibatkan kegiatan proses bisnis perusahaan } \\
\text { terganggu secara terbatas dalam } 1 \text { unit dan tidak } \\
\text { mempengaruhi pelayanan }\end{array}$ & 2 \\
\hline Medium & $\begin{array}{c}\text { Mengakibatkan kegiatan proses bisnis perusahaan } \\
\text { terganggu secara terbatas dalam } 1 \text { unit dan } \\
\text { mempengaruhi pelayanan }\end{array}$ & 3 \\
\hline Signifikan & $\begin{array}{l}\text { Mengakibatkan kegiatan proses bisnis perusahaan } \\
\text { terganggu secara terbatas dalam beberapa unit }\end{array}$ & 4 \\
\hline Malapetaka & $\begin{array}{l}\text { Mengakibatkan kegiatan proses bisnis perusahaan } \\
\text { terganggu secara terbatas dalam secara luas }\end{array}$ & 5 \\
\hline
\end{tabular}

\section{E. Business Continuity Plan}

Business Continuity Plan (BCP) Master Plan adalah dokumen manajemen yang menjelaskan metodologi untuk merangkai panduan aktifitas perencanaan untuk keberlangsungan bisnis (BCP), pemeliharaan, dan bagaimana BCP dieksekusi untuk mengembalikan operasi organisasi/ perusahaan setelah terjadi bencana.

\section{F. ISO 22301:2012}

ISO 22301 merupakan hasil dari pengembangan dari British Standard 25999-2:2007. Standar ISO 22301:2012 digunakan dalam rangka menjaga keberlangsungan bisnis dari adanya gangguan yang berpotensi mengancam bisnis perusahaan. Dalam penelitian ini, ISO 22301:2012 dijadikan sebagai kerangka dasar dalam menentukan arah berpikir dan pembentukan alur kerja didalamnya. Selain menggunakan standar ISO 22301, penelitian ini juga akan menggunakan contoh penerapan dari kerangka BCP yang telah diterapkan oleh perusahaan energi lain agar dapat disesuaikan dengan kebutuhan bisnis perusahaan yang dicontohkan dalam BCP perusahaan tersebut.

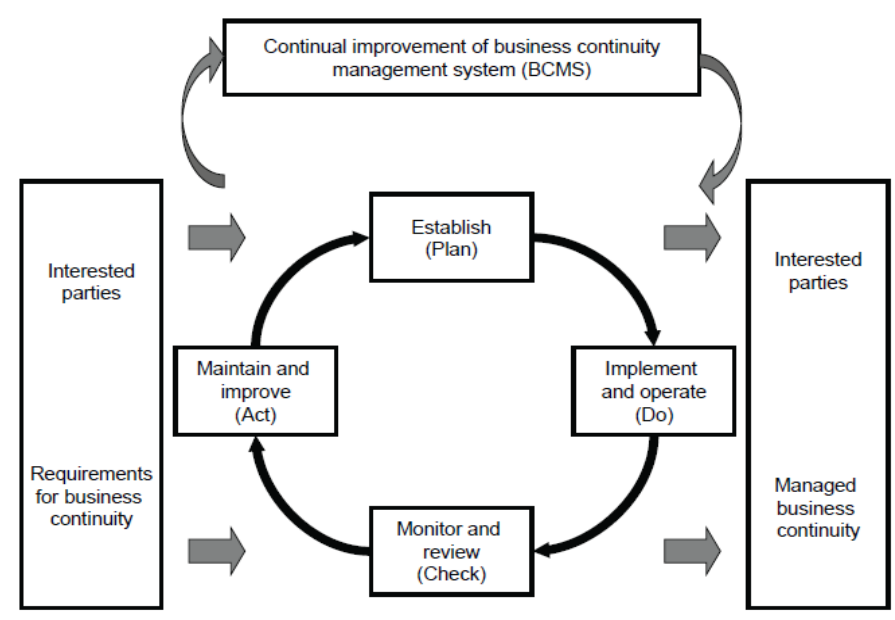

Gambar 1. Kerangka kerja ISO 22301:2012 


\section{G. Alur Kerja Terapan}

Alur kerja terapan yang digunakan dalam penelitian untuk BCP pada PT PLN (Persero) APD Jateng dan DIY adalah pada alur kerja yang diterapkan oleh Chubu Electric Power Company Group dari Jepang dan Department of Energy dari United States.

1) BCP pada Chubu Electric Power Company Group

Perusahaan Energi Chubu dari Jepang ini menerapkan pemberian ruang lingkup dari pelaksanaan BCPnya, namun alur kerja yang diberikan bersifat universal terhadap ruang lingkup tersebut. Ruang lingkup yang dipakai oleh perusahaan ini dalam pelaksanaan BCP didasarkan pada organisasi yang berkaitan, standar yang digunakan, serta masa berlaku BCP yang telah disusun.

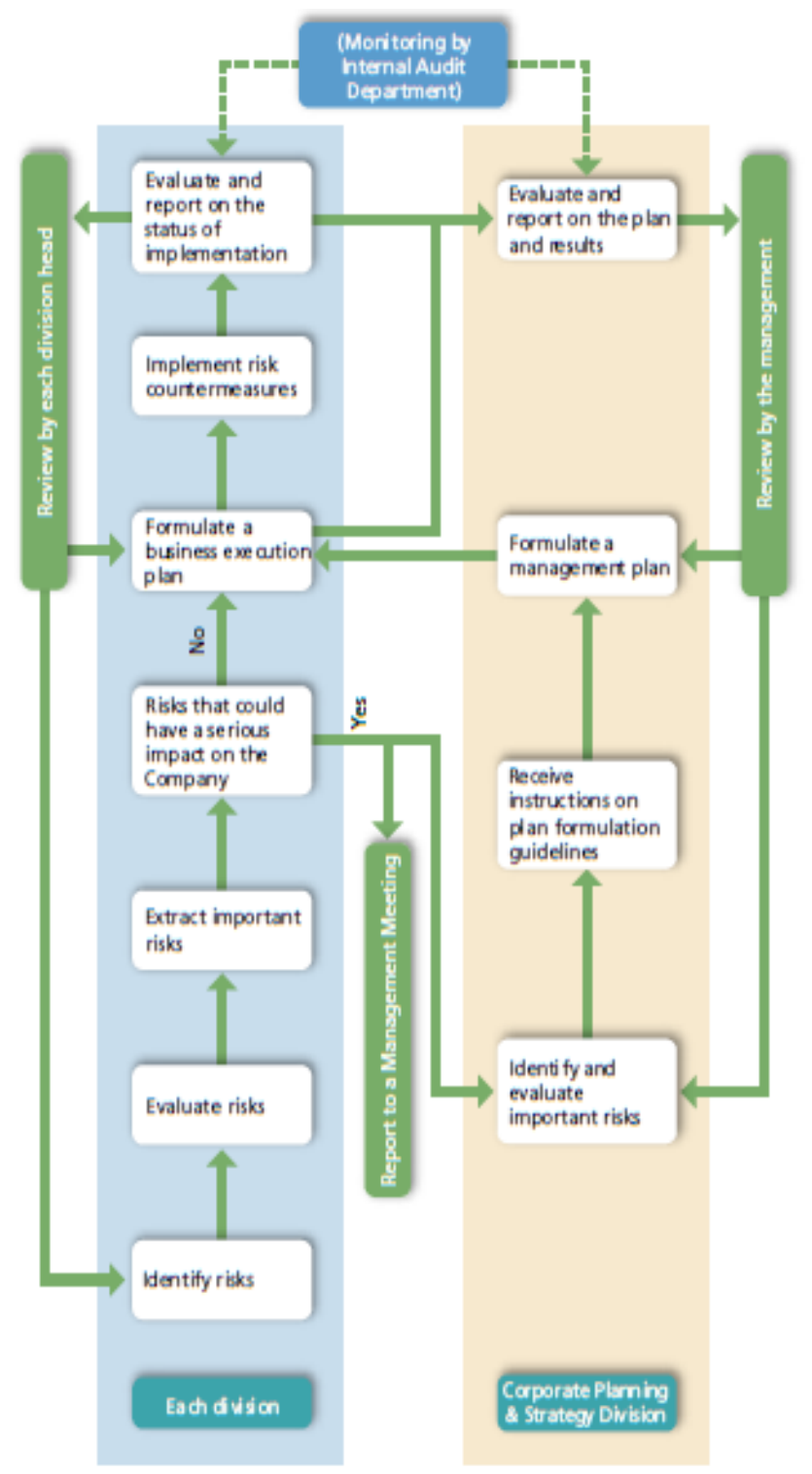

Gambar 2. Alur kerja keberlangsungan bisnis perusahaan chubu

\section{2) BCP pada Department of Energy United States}

Department of Energy merupakan organisasi atau perusahaan dari pemerintahan United States untuk mengatur sektor energi dan sektor perminyakan di United States [8].
Kerangka kerja tersebut dinamakan National Infrastructure Protection Plan (NIPP) Risk Management Framework.

Peran kerangka kerja ini dalam penelitian tugas akhir ini adalah dalam pemberlakuan metode yang dilakukan dalam beberapa proses dan pemberian rekomendasi perencanaan strategi keberlangsungan bisnis berdasarkan yang telah diterapkan oleh DOE.

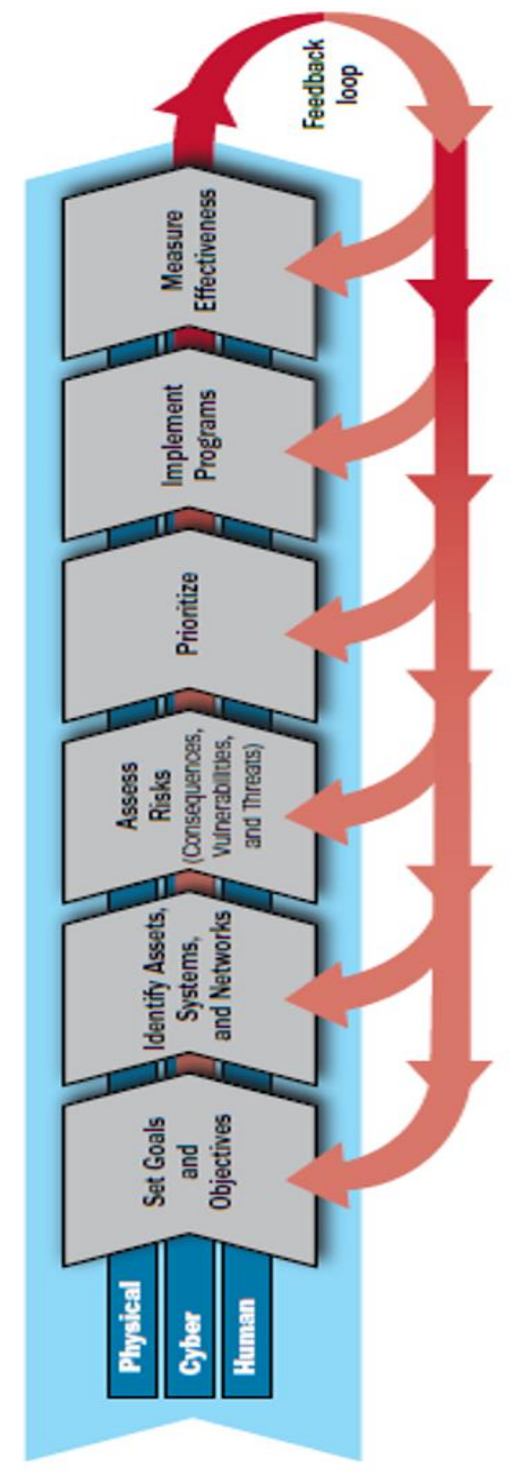

Gambar 3. NIPP risk management framework

\section{PERANCANGAN ALUR KERJA}

Sebelum melakukan penyusunan dokumen BCP untuk PT PLN (Persero) APD Jateng dan DIY, maka perlu dilakukan perancangan alur kerja $\mathrm{BCP}$ untuk perusahaan terkait terlebih dahulu sebagai panduan dalam proses penyusunan $\mathrm{BCP}$ untuk PT PLN (Persero) APD Jateng dan DIY pada penyusunan dokumen berikutnya.

Berikut merupakan bentuk visualisasi dalam proses perancangan alur kerja $\mathrm{BCP}$ : 

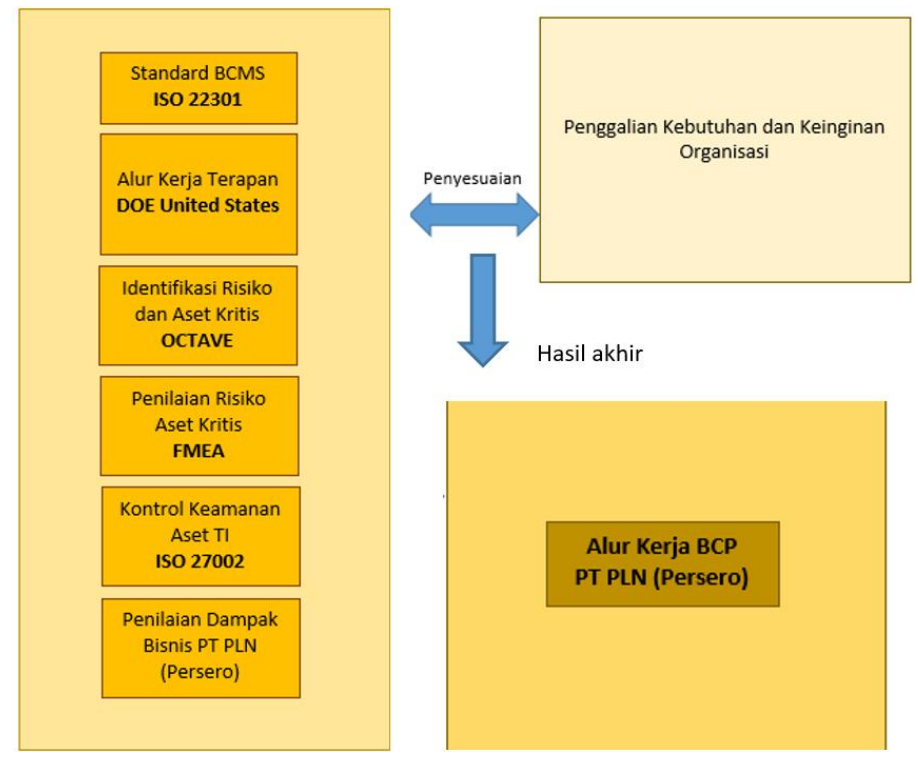

Gambar 4. Visualisasi Perancangan Alur Kerja BCP PT PLN (Persero) APD Jateng dan DIY

Perancangan alur kerja ini dimulai dengan melakukan studi empiris dan penyesuaian terhadap kebutuhan dan keinginan perusahaan terhadap perencanaan keberlangsungan bisnis. Studi empiris yang telah dilakukan sebagaimana pada bab tinjauan pustaka, merupakan pencarian dan pembelajaran terhadap standar- standar serta penerapan contoh alur kerja dan strategi keberlangsungan bisnis yang telah diterapkan pada perusahaan energi lainnya.

\section{A. Penggalian Kebutuhan Bisnis}

Penggalian kebutuhan bisnis dilakukan dengan menggali keinginan dan kebutuhan perusahaan terhadap pengerjaan $\mathrm{BCP}$ dengan metode wawancara denga pihak PT PLN (Persero) APD Jateng dan DIY.

Tabel 3.

Kebutuhan dan Keinginan Perusahaan terhadap BCP

\begin{tabular}{ll}
\hline \hline No & \multicolumn{1}{c}{ Keterangan } \\
\hline 1. & $\begin{array}{l}\text { BCP yang dibuat harus sesuai pada ketentuan rencana jangka panjang } \\
\text { PT PLN (Persero). }\end{array}$ \\
2. & $\begin{array}{l}\text { BCP melibatkan pada setiap proses bisnis yang terdapat pada PT PLN } \\
\text { (Persero) APD Jateng dan DIY. }\end{array}$ \\
3. & $\begin{array}{l}\text { BCP yang dibuat berdasarkan alur komunikasi yang dapat dijalankan } \\
\text { oleh SDM pada PT PLN (Persero) APD Jateng dan DIY. }\end{array}$ \\
4. & $\begin{array}{l}\text { BCP yang dibuat berdasarkan pada penggunaan aset atau layanan TI } \\
\text { dan dampak bisnis perusahaan. }\end{array}$ \\
5. & $\begin{array}{l}\text { BCP yang dibuat berdasarkan keberlanjutan pada proses bisnis } \\
\text { perusahaan. }\end{array}$ \\
6. & $\begin{array}{l}\text { Perusahaan dapat mengetahui kerentanan aset kritis TI berdasarkan gap } \\
\text { yang tidak dilakukan perusahaan berdasarkan standar keamanan }\end{array}$ \\
informasi bersertifikasi ISO.
\end{tabular}

Berikut merupakan hasil dari pemetaan alur kerja BCP yang telah dilakukan pada penelitian ini berdasarkan pada kerangka dasar ISO 22301: 2012.

Tabel 4.

Pemetaan Alur dan Penggunaan Standar pada Alur Kerja BCP

\begin{tabular}{lll}
\hline \hline Fase & Alur & Standar yang Digunakan \\
\hline$P L A N$ & Menetapkan konteks & $\bullet$ ISO 22301
\end{tabular}

- OCTAVE method (Proses 1 pada tahap 1)

- Visi dan misi PT PLN (Persero)

- Visi dan misi PT PLN (Persero) APD Jateng dan DIY

Menetapkan ruang lingkup

- OCTAVE method (Proses 1 pada tahap 1)

- Chubu Electric Power Company

Menetapkan peran dan • ISO 22301:2012 tanggung jawab

- Struktur organisasi PT PLN (Persero) APD Jateng dan DIY

- OCTAVE method (tahap 1)

- Chubu Electric Power Company

Menetapkan tujuan BCP

- ISO 22301:2012

- Hasil wawancara dengan Asisten Manajer SCADA dan telekomunikasi

- NIPP risk management framework

Menentukan Sumber Daya

- NIPP Risk Management Framework

- OCTAVE methods

- ISO 27002

Menentukan Alur Komunikasi

- NIPP risk management framework

- Alur komunikasi gangguan TI PT PLN (Persero) APD Jateng dan DIY

DO Identifikasi dan Analisis Risiko

Analisis Dampak

Bisnis

Prioritisasi

Strategi BCP

- OCTAVE Methods

- FMEA Methods

- NIPP Risk Management Framework

- Perhitungan dampak bisnis PT PLN (Persero)

- Perhitungan dampak bisnis PT PLN (Persero)

- ISO 27002:2005

- FISMA - NIST Best Practices Implementasi DOE United States

- Data center recovery strategy for DOE

Prosedur BCP ISO 22301:2012

Pelatihan dan pengujian

CHECK Audit Pelaksanaan

- ISO 22301:2012

- ISO 22301:2012

Peninjauan pihak manajemen

ACT Peningkatan secara terus menerus
- ISO 22301:2012

- ISO 22301:2012

B. Alur Kerja BCP untuk PT PLN (Persero) APD Jateng dan 


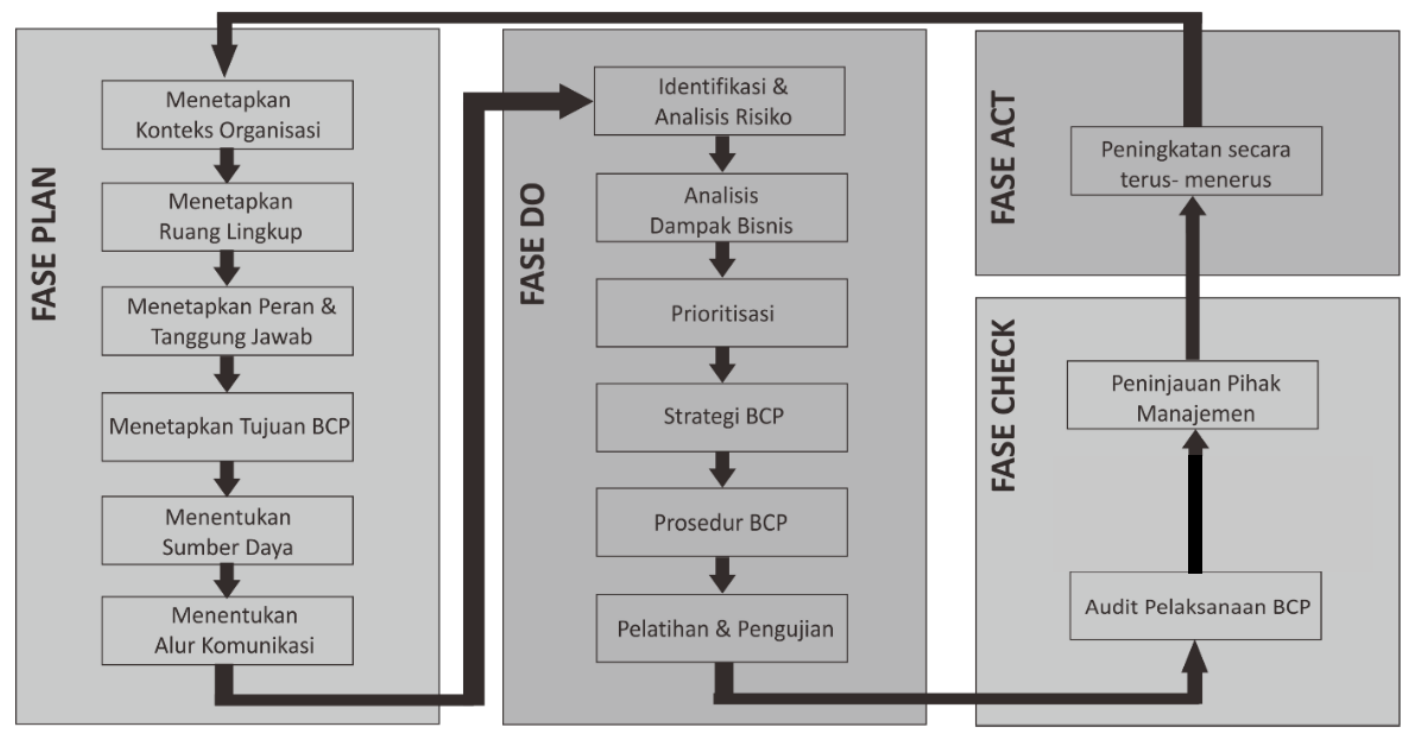

Gambar 5 Alur kerja BCP untuk PT PLN (Persero) APD Jateng dan DIY

Setiap proses pada alur kerja tersebut merupakan hasil dari formulasi studi empiris dan kebutuhan serta keinginan perusahaan terhadap pelaksanaan BCP pada PT PLN (Persero) APD Jateng dan DIY.

\section{IMPLEMENTASI}

\section{A. Fase Plan (Perencanaan)}

Fase ini menjelaskan konteks yang ada dalam lingkup organisasi, tujuan, alur komunikasi saat kejadian bencana/ gangguan yang mengancam proses bisnis serta pembagian peran dan tanggung jawab dari sumber daya yang akan dibutuhkan.

Konteks organisasi yang dilakukan adalah pada PT PLN (Persero) APD Jateng dan DIY dengan mengacu pada visi misi PT PLN pusat. Ruang lingkup yang digunakan adalah menggunakan metode identifikasi ruang lingkup perusahaan Chubu yang isinya disesuaikan dengan keadaan PT PLN (Persero) APD Jateng dan DIY. Peran dan tanggung jawab dibagi berdasarkan struktur organisasi yang terdapat dalam PT PLN (APD) Jateng dan DIY. Tujuan diidentifikasikan dari kebutuhan dan keinginan perusahaan terhadap penyusunan BCP. Sumber daya diiendtifikasikan berdasarkan identifikasi padakategori komponen sistem informasi perusahaan yang terdiri dari manusia, perangkat lunak, perangkat keras, data dan jaringan internet. Selanjutnya, pada proses menentukan alur komunikasi menggunakan alr komunikasi yang telah diterapkan oleh PT PLN (Persero) APD Jateng dan DIY.

\section{B. Fase Do (Pengerjaan)}

\section{1) Identifikasi dan Analisis Risiko TI}

Berdasarkan hasil identifikasi risiko TI dengan menggunakan metode OCTAVE serta analisis risiko dengan menggunakan penilaian FMEA, berikut merupakan hasil dari identifikasi dan analisis level risiko TI pada aset TI:
Tabel 5.

Tabel Level Risiko pada Aset TI

\begin{tabular}{cc}
\hline Aset TI & $\begin{array}{c}\text { Level Risiko Aset } \\
\text { TI }\end{array}$ \\
\hline SCADA & Very High \\
Server & \\
e-mail PLN & High \\
Network & \\
Data & Medium \\
Jaringan Internet & \\
Web Jaringan Distribusi & \\
Speedjardist & Low \\
PC & \\
Telepon Kantor & Very Low \\
People &
\end{tabular}

\section{2) Analisis Dampak Bisnis}

Analisa dampak bisnis dilakukan untuk mengetahui kritikalitas dampak bisnis pada tiap proses bisnis yang ditinjau dari 2 aspek yang telah ditetapkan pada buku manajemen risiko PT PLN (Persero). Penilaian ini dilakukan oleh tiap asisten manager fungsi bisnis yang menjalankan proses bisnis terkait. Berikut merupakan hasil dari analisis dampak bisnis:

Tabel 6.

Hasil Kritikalitas Dampak Bisnis

\begin{tabular}{|c|c|c|}
\hline No & Proses Bisnis & $\begin{array}{c}\text { Level } \\
\text { Kritikalitas } \\
\end{array}$ \\
\hline 1. & Pemeliharaan Korektif & High \\
\hline 2. & Operasional & High \\
\hline 3. & $\begin{array}{l}\text { Menyiapkan Keperluan Operasi } \\
\text { SCADA }\end{array}$ & High \\
\hline 4. & Remote Terminal Unit & High \\
\hline 5. & Pemeliharaan Intensif & Medium \\
\hline 6. & Proteksi dan Meter & Medium \\
\hline 7. & Pengelolaan TI dan telekomunikasi & Medium \\
\hline 8. & Pengelolaan data dan gambar & Low \\
\hline 9. & Perencanaan & Low \\
\hline 10. & Keuangan & Low \\
\hline 11. & Administrasi dan $\mathrm{K} 3$ & Low \\
\hline 12. & Kesiapan SDM & Low \\
\hline
\end{tabular}




\section{3) Prioritisasi}

Telah dilakukan prioritisasi dengan meninjau dari sisi kritikalitas proses bisnis serta level risiko dari aset TI yang dilakukan dengan bantuan matriks. Berikut merukapan hasil dari prioritisasi dari matriks tersebut

Tabel 7.

Hasil Prioritisasi Aset TI

\begin{tabular}{cll}
\hline \hline No & \multicolumn{1}{c}{ Aset TI } & \multicolumn{1}{c}{ Kritikalitas } \\
\hline 1. & SCADA & Prioritas Utama \\
2. & e-mail PLN & Prioritas Utama \\
3. & Server & Prioritas Utama \\
4. & Jaringan Internet & Prioritas Utama \\
5. & Data Perusahaan & Prioritas Utama \\
6. & SAP & Prioritas Menengah \\
7. & PC & Prioritas Menengah \\
8. & Telepon Kantor & Prioritas Menengah \\
9. & SAP & Prioritas Terakhir \\
10. & Finger Print & Prioritas Terakhir \\
11. & People & Prioritas Terakhir \\
12. & Telepon Kantor & Prioritas Terakhir \\
13. & Speedjardist & Prioritas Terakhir \\
\hline \hline
\end{tabular}

\section{4) Strategi Keberlangsungan Bisnis}

Strategi BCP yang akan dilakukan akan berdasarkan pada standar kontrol keamanan sistem informasi ISO 27002 dan pelaksanaan keberlangsungan bisnis berbasis risiko teknologi informasi pada Department of Energy (DOE) di United States.

Tabel 8.

Aset TI prioritas Utama dengan Medium dan High Risk

\begin{tabular}{|c|c|c|}
\hline No & Proses Bisnis & Kritikalitas \\
\hline 1. & SCADA & $\begin{array}{l}\text { Kesalahan konfigurasi pada SCADA } \\
\text { Peralatan pada Gardu Induk mengalami } \\
\text { kerusakan } \\
\text { Server untuk SCADA mengalami downtime } \\
\text { Tidak tersedianya jaringan listrik }\end{array}$ \\
\hline 2. & $e$-mail PLN & $\begin{array}{l}\text { Penyalahgunaan hak akses pada aplikasi } \\
\text { Server Down }\end{array}$ \\
\hline 3. & Server & $\begin{array}{l}\text { Kabel server terputus } \\
\text { Kelebihan memori pada RAM } \\
\text { Kesalahan pada konfigurasi server } \\
\text { Pencurian aset fisik pada server } \\
\text { Server dalam keadaan overheat }\end{array}$ \\
\hline 4. & $\begin{array}{l}\text { Data } \\
\text { Perusahaan }\end{array}$ & $\begin{array}{l}\text { Kesalahan pada konfigurasi backup dan } \\
\text { restore data }\end{array}$ \\
\hline 5. & $\begin{array}{l}\text { Jaringan } \\
\text { Internet }\end{array}$ & $\begin{array}{l}\text { Serangan hacker melalui jaringan internet } \\
\text { Kesalahan konfigrasi instalasi jaingan } \\
\text { internet } \\
\text { Gangguan pada kabel fiber optic } \\
\text { Terputusnya kabel LAN }\end{array}$ \\
\hline
\end{tabular}

Strategi pada keberlangsungan bisnis ini akan berdasarkan pada strategi preventif, strategi DRP, strategi detektif, serta strategi korektif.

\section{5) Prosedur $B C P$}

Prosedur BCP disusun berdasarkan pada kebutuhan strategi yang telah disusun sebelumnya. Berdasarkan strategi yang telah direncanakan pada proses sebelumnya, terdapat 11 usulan prosedur yang dibutuhkan dalam pelaksanaan kebelangsungan bisnis berbasisi risiko teknologi informasi pada PT PLN (Persero) APD Jateng dan DIY.

\section{6) Pelatihan dan Pengujian $B C P$}

Proses ini bertujuan untuk memastikan bahwa pihak organisasi memahami strategi yang dibuat serta untuk memastikan bahwa strategi yang dibuat telah sesuai dengan kebutuhan perusahan.

\section{Fase Check (Pemeriksaan)}

Pada fase ini akan dilakukan audit terhadap pelaksanaan $\mathrm{BCP}$ dan peninjauan manajemen terhadap $\mathrm{BCP}$, sehingga dari fase ini perusahaan dapat meninjau kesesuaian dan efektifitas dari pelaksanaan BCP pada PT PLN (Persero) APD Jateng dan DIY.

\section{Fase Act (Penindakan)}

Fase tindakan merupakan fase yang dilakukan oleh perusahaan untuk melakukan peningkatan terhadap kinerja BCP. Selain itu, pada fase ini juga dilakukan penilaian ulang terhadap pemberlakuan ruang lingkup, kebijakan, dan prosedur yang telah diberlakukan pada pelaksanaan BCP.

\section{KESIMPULAN DAN SARAN}

\section{A. Kesimpulan}

Penelitian ini telah menjawab rumusan masalah yang yang telah ditetapkan oleh peneliti. Berikut merupakan kesimpulan dari jawaban rumusan masalah yang telah dilakukan oleh peneliti:

1. Hasil dari analisis kritikalitas bisnis menunjukkan bahwa terdapat 6 proses bisnis pada PT PLN (Persero) APD Jateng dan DIY memiliki risiko tinggi dalam kritikalitas bisnis perusahaan. Diantaranya adalah proses bisnis operasional, proses bisnis pengelolaan data dan gambar, proses bisnis persiapan operasi SCADA, proses bisnis Remote Terminal Unit, serta proses bisnis pemeliharaan korektif. Sedangkan pada proses bisnis yang memiliki dampak kritikalitas risiko pada level medium adalah pasa proses bisnis perencanaan, proses bisnis pemeliharaan intensif, serta proses bisnis power dan meter. Sedangkan pada kritikalitas bisnis dengan level low adalah pada proses bisnis keuangan, administrasi dan K3, serta kesiapan SDM.

2. Hasil analisis dari prioritisasi pada aset TI berdasarkan pada penilaian dampak bisnis dan penilaian risiko aset TI menunjukkan bahwa terdapat 6 aset TI yang dijadikan sebagai prioritas utama dalam keberlangsungan bisnis, yaitu SCADA, e-mail PLN, Server, jaringan internet, speedjardist, serta data perusahaan.

3. Hasil perancangan alur kerja telah terjawab pada bahasan formulasi dan hasil perancangan alur kerja BCP pada jurnal ini.

4. Rekomendasi hasil akhir manajemen menunjukkan bahwa manajemen perlu melakukan beberapa pelaksanaan strategi yang meliputi strategi preventif, strategi detektif, strategi korektif, serta strategi DRP untuk penanganan gangguan layanan TI. Selain itu, manajemen juga perlu memberlakukan prosedur-prosedur terkait untuk 
pelaksanaan keberlangsungan bisnis pada PT PLN (Persero) APD Jateng dan DIY.

\section{B. Saran}

Keberlanjutan penelitian ini diharapkan dapat dilanjutkan dengan penelitian penyusunan prosedur yang telah ditetapkan pada strategi keberlangsungan bisnis, serta pelaksanaan BCP pada perusahaan sejenis.

\section{UCAPAN TERIMA KASIH}

Penulis A.A. mengucapkan terima kasih kepada PT PLN (Persero) APD Jateng dan DIY yang telah memberikan dukungan dan kesempatan kepada penulis dalam melakukan penelitian dengan studi kasus perusahaan PT PLN (Persero) APD Jateng dan DIY.

\section{DAFTAR PUSTAKA}

[1] ISO 3100, “ISO 3100 - Risk Management,” 2015.

[2] E. Blokdijk, "Risk Management," 2008.

[3] Software Engineering Institute, Operationally Critical Threat, Assets, and Vulnerability Evaluation (OCTAVE) Framework Version 1.0, Canada: SEI Carnegie Mellon University, 1999.

[4] J. Marshall, An Introductioan to Failure Modes Effects and Critically Analysisi (FMEA), Canada, 2012.

[5] P. Ravesh, Business Continuity Plan, Tata Concultancy Service, 2002.

[6] ISO 22317, ISO 22317, 2015 penyunt., Stockholm: SIS, 2015.

[7] PT PLN (Persero), "Rencana Jangka Panjang 2014 - 2018,” PT PLN (Persero), Jawa Tengah, 2014.

[8] United States Department of Energy, "Energy Sector-Specific Plan," Homeland Security, North America, 2010. 